\title{
Single-port laparoscopic surgery for ovarian cystectomy: A single-center analysis of 25 cases
}

\author{
KENTARO NAKAYAMA $^{1 *}$, YUKI YOSHIMURA ${ }^{1,2^{*}}$, SULTANA RAZIA $^{1 *}$, \\ HITOMI YAMASHITA ${ }^{1}$, TOMOKA ISHIBASHI ${ }^{1}$, MASAKO ISHIKAWA ${ }^{1}$, \\ HIROKI SASAMORI ${ }^{1}$, KIYOKA SAWADA ${ }^{1}$, SONOMI KUROSE ${ }^{1}$, \\ SEIYA SATO ${ }^{1}$ and SATORU KYO ${ }^{1}$ \\ ${ }^{1}$ Department of Obstetrics and Gynecology, Shimane University, Izumo, Shimane 6938501; \\ ${ }^{2}$ Department of Obstetrics and Gynecology, Hamada Medical Center, \\ Hamada, Shimane 6978511, Japan
}

Received April 22, 2020; Accepted May 7, 2021

DOI: $10.3892 / \mathrm{mco} .2021 .2322$

\begin{abstract}
Innovation in gynecological surgery is constantly evolving to make procedures less invasive. Minimally invasive single-port laparoscopic surgery (SPLS) is another innovation that may further improve gynecological surgery outcomes. However, SPLS is not widely used due to the technical difficulties of the procedure. Inserting several instruments through the same incision impedes proper use of the devices. Therefore, the present study aimed to find a technique to overcome this problem and make this approach more convenient. Between March 2015 and February 2020, 25 patients were treated with SPLS by a single gynecological surgeon. The range of surgery time was 50-103 min and the mean surgery time was $67.2 \mathrm{~min}$. The mean bleeding volume was small (mean, $10.1 \mathrm{ml}$ ). No intraoperative or postoperative complications occurred in the patients. A gel port (GelPOINT ${ }^{\circledR}$ Mini Medical Leaders) was inserted into the peritoneal cavity through a $3-\mathrm{cm} \mathrm{Z}$-shaped intra-umbilical skin incision. Additionally, a small incision $(3 \mathrm{~mm})$ was made in the left medial portion of the iliac crest and a bladeless trocar (Versa One ${ }^{\circledR}$ ) was inserted. Thus, crowding of the working instruments within one incision was prevented. The addition of a small diameter port (3-mm) at the wound site left practically no scar, thus making SPLS a cosmetically superior option compared with a bigger diameter port (5-mm).
\end{abstract}

Correspondence to: Dr Kentaro Nakayama, Department of Obstetrics and Gynecology, Shimane University, Enyacho 89-1, Izumo, Shimane 6938501, Japan

E-mail:kn88@med.shimane-u.ac.jp

*Contributed equally

Key words: single-port laparoscopic surgery, ovarian cystectomy, gynecology, ovarian tumor, minimally invasive

\section{Introduction}

Distinct surgical approaches for managing the same disease have several advantages and disadvantages when compared to each other. These factors may be related to the technical features and/or surgical team's comfort in performing the technique; yet, in any comparison, patient outcome measures are the highest priority. Any approach used in surgical oncology may become very popular for a limited period unless it has not been proven safe, feasible, and good for short, mid, and long-term patient outcomes. Single-port laparoscopic surgery (SPLS) is currently a popular option in gynecologic surgery. SPLS is a form of advanced, minimally invasive laparoscopic surgery that uses a specialized technique where one small incision provides laparoscopic access for optics and instruments. Recently, some reports have demonstrated the feasibility and safety of SPLS and the improvements in outcome over conventional laparoscopy in terms of pain, recovery time, cosmesis, and duration of hospital stay (1-6). However, SPLS is not widely available due to the technical difficulty of the procedure. It can be thought that inserting several instruments through the same incision impedes the proper working of the devices. The surgeon and the assistant must maneuver in a very small space outside the abdomen, which can result in hand collisions (7). On the other hand, in single-port surgery, no other port exists for scope placement and the ability to move the scope is significantly limited by other instruments (8). Therefore, the objective of this study was to overcome these technical challenges. Inserting a small diameter port $(3 \mathrm{~mm})$ associated with a trocar in the left medial part of the iliac crest could make this approach more comfortable geometrically. To our knowledge, this is the first report regarding this new technique.

\section{Materials and methods}

This retrospective study included 25 patients who underwent laparoscopic cystectomy at our institution between March 2015 and February 2020. Single-port procedures were performed with devices manufactured specifically 
A

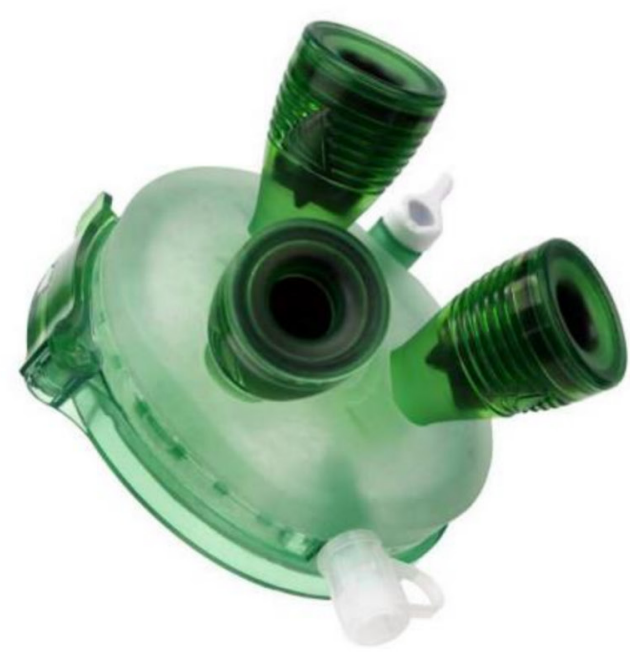

$\mathrm{B}$

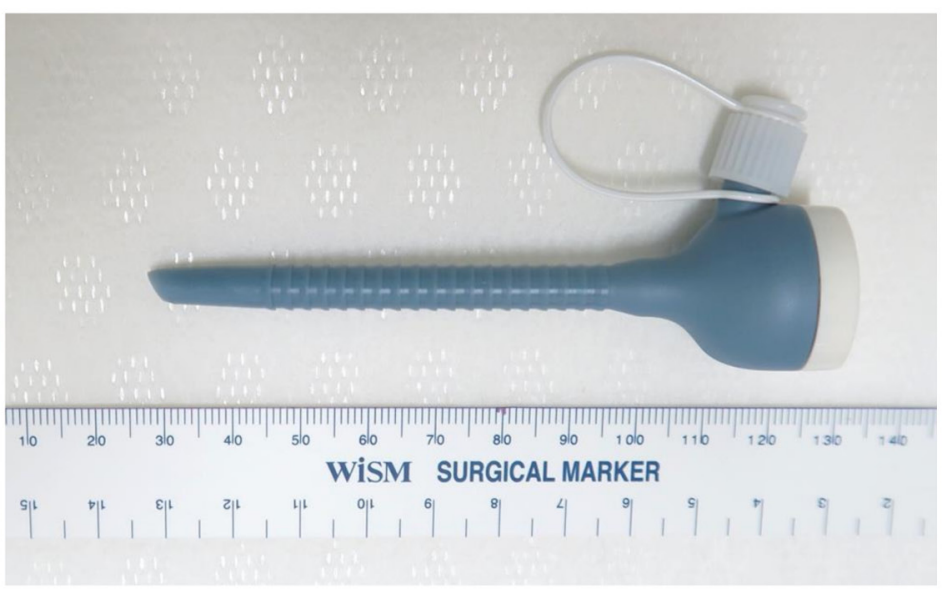

Figure 1. Devices manufactured specifically for single-port procedures. (A) GelPOINT ${ }^{\circledast}$ Mini Medical Leaders. (B) Bladeless trocar (Versa One ${ }^{\circledR}$.

for single-port procedures used in gynecologic surgery (GelPOINT ${ }^{\circledR}$ Mini Medical Leaders) (Fig. 1). Written informed consent for this operation was obtained from all patients or their parents/guardians (for patients $<18$ years old). This work was approved by the Institutional Review Board, Shimane University (IRB no. 201912120-1). After making a 3-cm Z-shaped intra-umbilical skin incision (Fig. 2), the gel port is inserted into the peritoneal cavity through the umbilicus associated with 2 trocars. In order to facilitate movement of surgeon's hands without collisions, a small incision $(3 \mathrm{~mm})$ is performed in the left medial part of the iliac crest and a bladeless trocar (Versa One ${ }^{\circledR}$ ) is inserted into this incision (Fig. 2). The main outcome measures chosen for the current analysis were total operation time, estimated blood loss during surgery, and changes in hemoglobin level. Data collected from the hospital database included age, body mass index, previous surgeries, preoperative symptoms, operation time, blood loss, and length of hospital stay.

\section{Results and Discussion}

A total of 25 patients who underwent laparoscopic ovarian cystectomy using our new technique were included in this study. The mean patient was 27.8 (range, 15-39) years. The mean total surgery time was 67.2 (range, 50-1,030) min. The mean blood loss was 10.1 (range, $0-100) \mathrm{ml}$. The mean postoperative hospital stay was 4.2 (range, 3-8) days (Table I). No intraoperative or postoperative complications occurred in any of the patients.

The percent of cases of benign disease being managed with SPLS has increased dramatically in recent years (1-6). It has been reported that SPLS has several advantages compared to conventional laparoscopy in the gynecologic field, such as less post-operative pain, less recovery time, better cosmesis, and less hospital stay (1-6). SPLS is also useful for specimen removal because of the large umbilical port site $(2,3)$. However, SPLS has a major systemic limitation: It involves crowding of all the working instruments
Table I. Patient demographics $(n=25)$.

Variable

Value

Age, years

Mean

Range

Surgery time, $\min$

Mean

Range

Bleeding volume, $\mathrm{ml}$

Mean

Range

Postoperative hospital stay, days

Mean

Range

within one incision. As a result of this, visualization may be obscured and hand collisions may occur between the surgeon and assistant during the procedure. These technical problems cause lower surgical accuracy and longer operation time compared to conventional laparoscopy. Another limitation is that SPLS is a difficult procedure, at least initially; it becomes easier with increasing experience of the surgeon and development of instruments (8). When related to inadequate training and experience, these challenges may increase the risk of intraoperative injury. To overcome the technical difficulties of SPLS, newly developed approaches have been introduced in our hospital since 2015. A small incision $(3 \mathrm{~mm})$ is performed in the left medial part of the iliac crest and a bladeless trocar (Versa One $\left.{ }^{\circledR}\right)$ is inserted into this incision (Fig. 2). A 3-mm bipolar forceps are included in this trocar. This ensures adequate distance between the incisions of umbilicus as well as abdominal wall, facilitating 


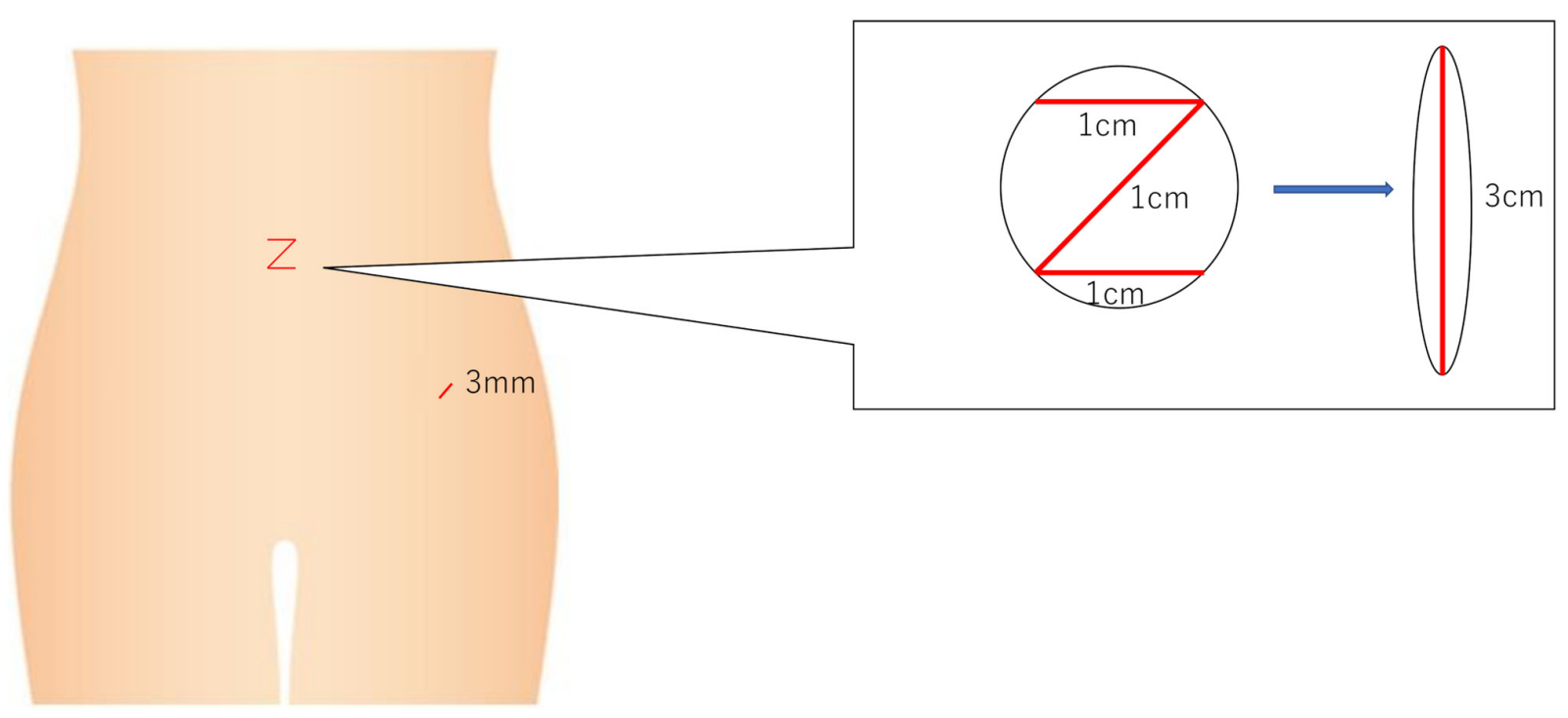

Figure 2. Z-shaped skin incision method at navel and 3-mm incision in left iliac region.

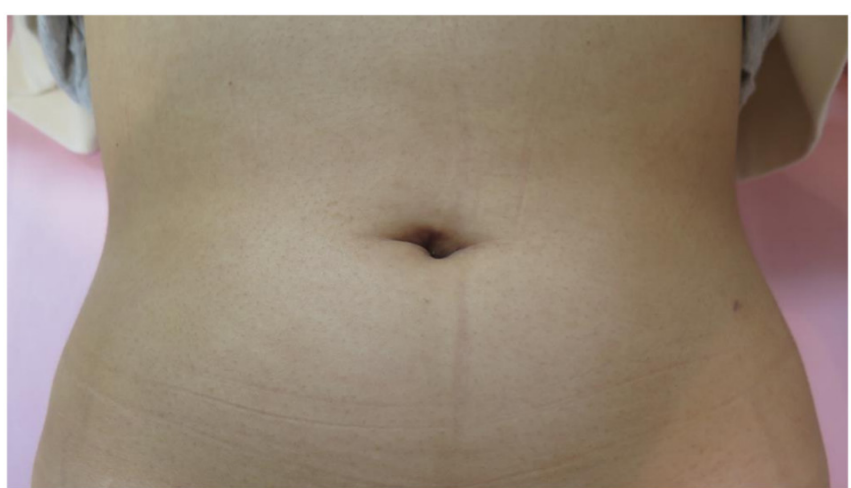

Figure 3. Inserting small diameter port $(3 \mathrm{~mm})$ associated with trocar in the left medial of iliac crest leaves practically no scare.

easy movement of the surgeon's hands without collisions. As a result, even younger and/or less experienced doctors can perform this procedure safely and easily. On the other hand, due to the addition of a small diameter port, there is practically no scar at the wound site, making SPLS cosmetically a superior option (Fig. 3).

There are some limitations to our study. First, a small number of patients were included in our study, making it difficult to draw a clear-cut conclusion about the findings. Therefore, further investigation with a larger study population is required. Moreover, the surgical outcomes of procedures performed by only one surgeon were analyzed. Therefore, it may be difficult to extrapolate our findings. Consequently, further randomized controlled trials are necessary.

In conclusion, by using $\mathrm{Z}$ shape intra-umbilical skin incision and including an additional small diameter port, interference of forceps as well as hand collision among surgeons is prevented. We hope that as the chief technical difficulties in this procedure have been overcome, SPLS will be an increasingly widespread minimally invasive procedure in the gynecologic field.

\section{Acknowledgements}

Not applicable.

\section{Funding}

No funding was received.

\section{Availability of data and materials}

The datasets used and/or analyzed during the current study are available from the corresponding author on reasonable request.

\section{Authors' contributions}

KN and SR drafted the manuscript. KN and SR confirm the authenticity of all the raw data. TI, MI, SS, HY, KS, YY, SR, $\mathrm{SKu}$ and HS performed the operation and statistical analysis. KN participated in the design of the study. SKy conceived the study, participated in its design and coordination, and helped in drafting the manuscript. All authors have read and approved the final manuscript.

\section{Ethics approval and consent to participate}

Written informed consent was obtained from all patients or their parents/guardians (for patients $<18$ years old). The present study was approved by the Institutional Review Board of Shimane University (approval no. 201912120-1).

\section{Patient consent for publication}

Consent was obtained from a patient for the publication of corresponding images.

\section{Competing interests}

The authors declare that they have no competing interests. 


\section{References}

1. Jung YW, Kim SW and Kim YT: Recent advances of robotic surgery and single-port laparoscopy in gynecologic oncology. J Gynecol Oncol 20: 137-144, 2009.

2. Jung YW, Choi YM, Chung CK, Yim GW, Lee M, Lee SH, Paek JH, Nam EJ, Kim YT and Kim SW: Single port transumbilical laparoscopic surgery for adnexal lesions: A single center experience in Korea. Eur J Obstet Gynecol Reprod Biol 155: 221-224, 2011.

3. Yim GW, Jung YW, Paek J, Lee SH, Kwon HY, Nam EJ, Kim S, Kim JH, Kim YT and Kim SW: Transumbilical single-port access versus conventional total laparoscopic hysterectomy: Surgical outcomes. Am J Obstet Gynecol 203: 26.e1-e6, 2010.

4. Escobar PF, Bedaiwy MA, Fader AN and Falcone $\mathrm{T}$ : Laparoendoscopic single-site (LESS) surgery in patients with benign adnexal disease. Fertil Steril 93: 2074.e7-e10, 2010.

5. Fader AN and Escobar PF: Laparoendoscopic single-site surgery (LESS) in gynecologic oncology: Technique and initial report Gynecol Oncol 114: 157-161, 2009.
6. Lee YY, Kim TJ, Kim CJ, Kang H, Choi CH, Lee JW, Kim BG, Lee JH and Bae DS: Single-port access laparoscopic-assisted vaginal hysterectomy: A novel method with a wound retractor and a glove. J Minim Invasive Gynecol 16: 450-453, 2009.

7. Paek J and Kim SW: Single-port access laparoscopic surgery in gynecology: Technical tips, advanced gynecologic endoscopy. Darwish A (ed). In Tech, 2011. Available from: http://www.intechopen.com/books/advanced-gynecologic-endoscopy/single-portaccess-laparoscopic-surgery-in-gynecology-technical-tips.

8. Lee M, Kim SW, Nam EJ, Yim GW, Kim S and Kim YT: Single-port laparoscopic surgery is applicable to most gynecologic surgery: A single surgeon's experience. Surg Endosc 26: 1318-1324, 2012.

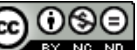

This work is licensed under a Creative Commons Attribution-NonCommercial-NoDerivatives 4.0 International (CC BY-NC-ND 4.0) License. 